\title{
Influência da intangibilidade e da responsabilidade social corporativa na geração de valor adicionado
}

\section{Influence of intangibility and corporate social responsibility in generating added value}

\author{
Cristian Rebonatto ${ }^{1}$, Camila Ascari², Luís André Colpani dos Santos ${ }^{3}$, Sady Mazzioni ${ }^{4}$, Cristian Baú Dal \\ Magro $^{5}$
}

Recebido: 21/07/2020. Aceito: 14/09/2020

\begin{abstract}
Resumo
O objetivo deste estudo é o de verificar a influência da intangibilidade e da Responsabilidade Social Corporativa (RSC) na geração de valor adicionado em companhias abertas listadas na bolsa de valores Brasil, Bolsa, Balcão. A pesquisa caracteriza-se como descritiva, conduzida por coleta documental e com abordagem predominantemente quantitativa. Utilizou-se da regressão linear múltipla para analisar os dados relativos ao ano de 2018 de uma amostra composta por 193 companhias. Os resultados mostram que, individualmente, a intangibilidade das companhias investigadas influencia na maior geração de valor adicionado. Em relação ao papel moderador, o desempenho em RSC anula o efeito positivo da intangibilidade; mantém a influência negativa do crescimento de vendas e da governança corporativa, reduzindo a força; mantém a influência positiva do tamanho da empresa, reduzindo a força. Contudo, os resultados indicam inconsistência na influência da RSC sobre a geração de valor adicionado. Os resultados contrariam a premissa de que a RSC, ao fortalecer a reputação corporativa, pode melhorar o desempenho organizacional mensurado pelo valor adicionado.
\end{abstract}

Palavras-chave: Valor adicionado. Intangibilidade. Responsabilidade Social Corporativa.

\begin{abstract}
The objective of the study is to verify the influence of intangibility and Corporate Social Responsibility (CSR) in the generation of added value in public companies listed on the stock exchange Brazil, Bolsa, Balcão. The research is characterized as descriptive, conducted by documentary collection and with a predominantly quantitative approach. Multiple linear regression was used to analyze data from a sample of 193 companies, for the year 2018. The results show that, individually, the intangibility of the investigated companies influences the greater generation of added value. In relation to the moderating role, the performance in CSR nullifies the positive effect of intangibility; maintains the negative influence of sales growth and corporate governance, reducing strength; maintains the positive influence of company size, reducing strength. However, the results indicate inconsistency in the influence of CSR on the generation of added value. The results contradict the premise that CSR by strengthening corporate reputation can improve organizational performance measured by added value.
\end{abstract}

Keywords: Added value. Intangibility. Corporate social responsibility.

1 Mestrando em Ciências Contábeis e Administração (UNOCHAPECÓ). E-mail: cristianrebonatto@unochapeco.edu.br

2 Graduanda em Ciências Contábeis (UNOCHAPECÓ). E-mail: kamila.ascari@gmail.com

3 Graduando em Ciências Contábeis (UNOCHAPECÓ). E-mail:luisandrecds@hotmail.com

4 Doutor em Ciências Contábeis e Administração (FURB). Prof. Mestrado em Ciências Contábeis e Administração (UNOCHAPECÓ). E-mail: sady@unochapeco.edu.br

5 Doutor em Ciências Contábeis e Administração (FURB). Prof. Mestrado em Ciências Contábeis e Administração (UNOCHAPE-

CÓ). E-mail: crisbau@unochapeco.edu.br 


\section{Introdução}

Os ativos intangíveis são caracterizados como sinônimos de ativos intelectuais, recursos intangíveis, capital intelectual e goodwill (CRAWFORD, 1994; SVEIBY, 1998; MOURA, 2011), constituindo-se em componente relevante para a formação do valor econômico nas organizações (KAYO et al, 2006). São compreendidos como elementos que não possuem matéria, são invisíveis, não podem ser tocados (a exemplo das marcas, patentes, franquias, licenças e softwares), entretanto, são controláveis e apresentam expectativa de geração de benefícios econômicos futuros que fluíram pelas empresas (PEREZ; FAMÁ, 2006).

A obtenção de vantagem competitiva duradoura, geralmente, está associada aos ativos intangíveis, por agregarem recursos raros e valiosos que são difíceis de serem imitados ou substituídos pelos concorrentes (ANDONOVA; RUÍZ-PAVA, 2016). Ademais, Lorena (2018) chama a atenção para a relevância singular da Responsabilidade Social Corporativa (RSC) na criação de vantagem competitiva, tendo como função melhorar a reputação corporativa para atrair e reter clientes e manter o capital intelectual.

As partes interessadas esperam que as empresas se comportem de maneira ética e os investidores estão mais interessados em empresas que praticam a RSC, fortalecendo a premissa de que a reputação corporativa pode aumentar o valor da empresa (HOU, 2018). Estudos anteriores destacaram o papel da visibilidade da empresa (MARTÍNEZ-FERRERO; FRÍAS-ACEITUNO, 2015) e a atenção das partes interessadas (MADSEN; RODGERS, 2015) para vincular a RSC ao desempenho financeiro. Os achados revelam relação positiva entre RSC e desempenho organizacional.

O desempenho organizacional pode ser melhorado com as ações de RSC e dos ativos intangíveis, esperando-se reflexo também na geração de valor adicionado das empresas (LUCA et al., 2009). O valor adicionado é uma medida do desempenho econômico, reconhecido como um incremento na riqueza das entidades. Esta medida incorpora informações econômicas e sociais, identificando a parcela de participação de cada uma das partes no processo, revelando o resultado da empresa (HALLER; STOLOWY, 1998).

As evidências empíricas dos estudos prévios têm demonstrado a influência positiva entre os intangíveis e o desempenho empresarial (MOURA, 2011; MAZZIONI; CARPES; LAVARDA, 2014; MAZZIONI; MOURA; HEIN, 2014) e a influência positiva da RSC no desempenho empresarial (CALLAN; THOMAS, 2009; MARTI; ROVIRA-VAL; DRESCHER, 2015; MARTÍNEZ-FERRERO; FRÍAS-ACEITUNO, 2015; BUSCH; FRIEDE, 2018; HOU, 2018).

Outros estudos, a exemplo de Madorran e Garcia (2016), Vergini et al. (2015), Zanelato et al. (2018) encontraram relação neutra, em que não há influência entre RSC e desempenho. Por sua vez, Oliveira, Silva Junior e Silva (2010) e Roque e Cortez (2006), encontraram relação negativa entre os investimentos sociais e o desempenho financeiro das empresas listadas na bolsa brasileira.

Embora seja reconhecida a existência da relação entre os ativos intangíveis e a RSC, e dos resultados não definitivos entre RSC e desempenho organizacional, não foram identificados estudos que utilizam os dois fatores, de forma concomitante e moderada para explicar o desempenho organizacional na perspectiva da ge- 
ração de valor adicionado.

A partir do contexto apresentado, surge a pergunta de pesquisa que orienta este estudo: qual a influência da intangibilidade e da Responsabilidade Social Corporativa na geração de valor adicionado? O estudo tem por objetivo verificar a influência da intangibilidade e da Responsabilidade Social Corporativa na geração de valor adicionado em companhias abertas listadas na bolsa de valores Brasil, Bolsa, Balcão - [B³].

Em virtude da ausência de reconhecimento, evidenciação e mensuração dos reflexos produzidos pelas práticas de RSC nos ativos intangiveis, a exemplo das marcas e do capital intelectual, justifica-se o uso concomitante dos fatores de RSC e intangibilidade para explicar o desempenho organizacional.

\section{Revisão da literatura}

A revisão da literatura contribui na sustentação da temática proposta e apresenta abordagens sobre a RSC, intangibilidade e valor adicionado, discutindo as possíveis relações entre as variáveis do estudo.

\subsection{Intangibilidade e desempenho organizacional}

O CPC 04 define ativo intangível como um ativo não monetário identificável sem substância física e que satisfaz o critério de identificação quando for: separável (vendido, trocado, transferido, alugado), individualmente ou junto a um contrato, ativo ou passivo e quando resultar de direitos contratuais, independente se for transferível ou separável da entidade (COMITÊ DE PRONUNCIAMENTO CONTÁBIL, 2010).

Diante do conceito de ativo intangível, cumpre ressaltar que a evolução tecnológica e a globalização dos mercados provocam mudanças constantes no mundo corporativo e aumento da competitividade, estimulando as empresas a buscarem novas alternativas que se consolidam muitas vezes, pela formação de ativos intangíveis (CALLADO; BOMFIM; SILVA, 2019).

Vale ressaltar que alguns intangíveis não são reconhecidos e mensurados a exemplo da RSC, dos recursos humanos e a estrutura da organização, entretanto, são fontes de vantagem competitiva capazes de gerar valor e melhorar o desempenho organizacional (GONZÁLES, 2014).

A intangibilidade pode promover um desempenho superior das firmas, tendo em vista que itens intangíveis não são comercializáveis e na maioria das vezes são criados para atender às demandas específicas de determinada empresa, sendo inimitáveis e representando grande potencial para geração de riqueza (CARVALHO; KAYO; MARTIN, 2010).

Um exemplo de elemento intangível difícil de ser copiado e praticamente inimitável é a reputação corporativa, caracterizada por alto nível de especificidade que impede a sua imitação (ANDONOVA; RUÍZ-PAVA, 2016). Desse modo, as empresas com reputação positiva devido a sua transparência, confiabilidade e sustentabilidade possuem diferencial diante da concorrência, ao retratar fatores ambientais e sociais politicamente corretos (CASTRO, 2016). 
Em decorrência da facilidade em adquirir tangíveis, a empresa que consegue reconhecer, mensurar e registrar os ativos intangíveis assume diferencial competitivo e maior geração de valor adicionado. Portanto, as organizações que investem, por exemplo, em capital intelectual ou em pesquisas para desenvolver novas tecnologias, podem se destacar (VOGT et al., 2016).

Mazzioni, Moura e Hein (2014) constataram que há uma relação positiva entre a intangibilidade e o valor adicionado e que os setores econômicos que mais investiram em ativos intangíveis obtiveram maior geração de valor adicionado. Resultados semelhantes também foram encontrados por Dallabona, Mazzioni e Klan (2015).

Ferla, Muller e Klann (2019) apontam existência da relação positiva entre a intangibilidade e desempenho, constando que pesquisa e desenvolvimento, marcas e patentes são itens intangíveis mais recorrentes nas empresas. O estudo de Silva, Callado e Bomfim (2019) revelaram a importância dos ativos intangíveis no desempenho das organizações, sendo capazes de gerar benefícios econômicos e influenciar na lucratividade.

Diante do exposto, propõe-se a seguinte hipótese:

$\mathrm{H}_{1}$ : os ativos intangíveis afetam positivamente a geração de valor adicionado.

\subsection{Responsabilidade social corporativa e desempenho organizacional}

A RSC pode ser uma alternativa para os gestores maximizarem o valor da empresa no longo prazo com o intuito de promover melhorias no relacionamento com fornecedores, clientes e colaboradores. Os benefícios das práticas de RSC podem superar os custos de implantação ainda no curto prazo, melhorando o desempenho das companhias (DUQUE; SILVA; COHEN, 2019).

A RSC está positivamente relacionada com o desempenho financeiro, com destaque para a reputação da organização (ORLITZKY; SCHMIDT; RYNES, 2003), ressaltando-se a relevância da divulgação das informações sociais e ambientais para melhorar a comunicação e visibilidade da empresa junto aos stakeholders (DUQUE; SILVA; COHEN, 2019), além, de conduzir a crescente demanda dos consumidores e maior produtividade dos colaboradores (CRAMER, 2003). Sendo assim, as empresas que não adotam práticas de RSC podem contribuir com o aumento dos acidentes de trabalho, problemas de saúde nos trabalhadores, poluição ambiental, refletindo na reputação e no desempenho organizacional (WANG, 2011).

A RSC está sujeita a constantes modificações, pois, o conceito pode tomar novas formas à medida em que houver mudanças no mundo corporativo relacionadas às questões ambientais, direitos humanos, saúde, segurança e o pagamento dos impostos que também é considerado um elemento da RSC, tendo em vista que direta ou indiretamente serão revertidos para o bem-estar da sociedade (NEVES; ALBUQUERQUE, 2019).

Uma forma indireta para relacionar a RSC como diferencial competitivo é comparar e analisar os resultados financeiros. Sendo assim, investimentos persistentes em ações socialmente responsáveis podem elevar os rendimentos no longo prazo e melhorar a performance das empresas no mercado (RIVES; BAÑÓN, 2008).

Por meio da meta-análise da relação entre a performance social corporativa e a performance financeira 
corporativa, a pesquisa de Silva, Boaventura e Mello (2018) aponta que a literatura indica três possibilidades de relação entre a performance social e financeira, sendo: (i) relação positiva, em que o aumento da performance social promove o aumento no desempenho financeiro; (ii) neutra, em que não há relação e mesmo que houvesse não pode ser identificada devido às dificuldades de mensuração; e, (iii) negativa, em que investimentos para melhorar a performance social piora a performance financeira da organização.

Na mesma perspectiva, a vantagem competitiva proporcionada pelas decisões socialmente responsáveis, permitem melhorar o desempenho financeiro das empresas (CALLAN; THOMAS, 2009; MARTI; ROVIRA-VAL; DRESCHER, 2015). Esta relação positiva entre RSC e desempenho organizacional foi documentada por Martínez-Ferrero e Frías-Aceituno (2015), Popoli (2015), Busch e Friede (2018), Hou (2018), Silva, Boaventura e Mello (2018) cujos estudos apontam que a RSC é um fator importante na melhoria do desempenho financeiro e social.

Por outro lado, ao pesquisar a RSC e o desempenho financeiro com dados de 208 empresas espanholas listadas no índice IBEX 35 entre os anos de 2003 e 2010, exceto do ramo financeiro, Madorran e Garcia (2016) evidenciaram uma relação neutra. A relação neutra entre RSC e desempenho organizacional também foi evidenciada por Vergini et al. (2015), cuja amostra do estudo foi composta por 5 empresas brasileiras listadas no Dow Jones Sustainability, entre 2009 e 2013. Já o estudo de Zanelato et al. (2018) não identificou relação entre RSC e desempenho em uma amostra composta por 22 empresas pertencentes ao Índice de Sustentabilidade Empresarial (ISE), entre os anos de 2010 e 2015, totalizando 102 observações.

Oliveira, Silva Junior e Silva (2010) encontraram relação negativa entre os investimentos sociais e o desempenho financeiro das empresas listadas na bolsa brasileira, cuja amostra foi composta por 43 empresas com dados referentes ao ano de 2002, 52 empresas em 2003 e 42 empresas em 2004. A relação negativa entre RSC e desempenho também foi encontrada nos estudos de Roque e Cortez (2006), indicando pior performance financeira das 35 empresas não financeiras listadas na Euronext Lisboa entre os anos de 2000 e 2004 que divulgaram informações ambientais.

Diante do exposto, propõe-se a seguinte hipótese:

$\mathrm{H}_{2}$ : a Responsabilidade Social Corporativa afeta a geração de valor adicionado.

\subsection{Responsabilidade social corporativa e formação de intangíveis}

As ações sociais e ambientais desenvolvidas ajudam a formar a reputação da empresa, um intangível difícil de imitar, do qual se espera que eleve os lucros financeiros e melhore o desempenho (BUSCH; FRIEDE, 2018). Assim, espera-se que exista relação entre RSC e os ativos intangíveis, tendo em vista que a RSC tem contribuído positivamente na melhoria da reputação das empresas e influenciado nos ativos intangíveis (GRECEANU, 2008; ROBINSON et al., 2011; SEARCY; ELKHAWAS, 2012).

Medeiros e Mol (2015) sustentam que os recursos específicos e indisponíveis aos concorrentes, a exemplo dos ativos intangíveis, permitem melhores resultados e contribui para um desempenho persistente. Vogt et 
al. (2016) explicam que em 2008 tornou-se obrigatória a apresentação das informações de caráter social nos relatórios das empresas listadas, a exemplo da remuneração dos proprietários e pagamento das obrigações, cujas informações são evidenciadas por meio da demonstração de valor adicionado.

Empresas com reputação socialmente responsável são mais reconhecidas pelos funcionários, considerando que são moldados pela sociedade e acreditam que a organização reconhece seus valores. Consequentemente, esta aceitação da empresa por parte do colaborador resulta em comprometimento organizacional. Com isso, ações voltadas a RSC desenvolvem benefícios intangíveis de caráter qualitativo, não quantificáveis (reputação, compromisso e aprendizagem) gerando benefícios tangíveis (redução na rotatividade de colaboradores, eficiência e redução dos custos operacionais), com reflexos nos resultados futuros (CHONG; TANG, 2008).

A RSC envolve ações capazes de promover benefícios internos e externos à empresa. Os benefícios internos resultantes das atividades socialmente responsáveis estão relacionados com a criação de recursos intangíveis pelos próprios colaboradores. Os benefícios externos relacionam-se principalmente com a reputação corporativa que é compreendida como um recurso intangível (BRANCO; RODRIGUES, 2006).

Os conhecimentos dos colaboradores ligados a uma determinada organização são considerados fatores qualitativos e recursos intangíveis, contudo, não é possível controlá-los. Portanto, as organizações devem promover ações que estimulem a motivação, a moral e o compromisso dos colaboradores para com a empresa. Sendo assim, a origem e o desenvolvimento do conhecimento dos colaboradores são de caráter social, provenientes das ações de RSC (BRANCO; RODRIGUES, 2006).

Diante do exposto, propõe-se a seguinte hipótese:

$\mathrm{H}_{3}$ : os ativos intangíveis afetam positivamente a relação entre a responsabilidade social corporativa e a geração de valor adicionado.

\section{Procedimentos metodológicos}

A fim de possibilitar o alcance dos objetivos e a resolução do problema de pesquisa proposto, do ponto de vista metodológico a pesquisa caracteriza-se como explicativa, conduzida por coleta documental (base de dados) e com abordagem predominantemente quantitativa.

A população da pesquisa está relacionada com as companhias abertas listadas na bolsa de valores brasileira, denominada Brasil, Bolsa, Balcão [ $\left.\mathrm{B}^{3}\right]$. Para a definição da amostra investigada foram excluídas as empresas do setor financeiro, em razão das peculiaridades da atividade econômica desenvolvida, além daquelas que não possuíam informações necessárias para operacionalizar todas as variáveis utilizadas, totalizando uma amostra de 193 companhias.

As variáveis e suas respectivas métricas estão detalhadas no constructo apresentado no Quadro 1. Os dados coletados referem-se ao exercício de 2018, período mais recente disponível para todas as variáveis na data da coleta. Em seguida procedeu-se a análise, por meio de estatística univariada e multivariada. Para validar os 
resultados da regressão linear múltipla, foram observados os pressupostos de normalidade, por meio do teste de Kolmogorov-Smirnov; multicolinearidade, por meio do fator de inflação de variância - VIF e Tolerance; homocedasticidade; e ausência de autocorrelação serial, pelo teste de Durbin-Watson.

Quadro 1 - Constructo da pesquisa

\begin{tabular}{|c|c|c|c|}
\hline Variável Dependente & Métrica & Fonte de dados & Autores de base \\
\hline $\begin{array}{l}\text { Geração do valor } \\
\text { adicionado (VA) }\end{array}$ & Logaritmo do valor adicionado & DVA - Site $[\mathrm{B}]^{3}$ & Luca et al. (2009) \\
\hline Variáveis Independentes & Métrica & Fonte de dados & Autores de base \\
\hline $\begin{array}{l}\text { Índice de } \\
\text { Responsabilidade } \\
\text { Social Corporativa } \\
\text { (IRSC) }\end{array}$ & $\begin{array}{l}\text { Escala de } 0 \text { a } 100 \text {, sendo que quanto } \\
\text { mais próximo de } 100 \text {, melhor a RSC. }\end{array}$ & CSRHub (2018) & $\begin{array}{l}\text { Arminen et al. } \\
\text { (2018); Keong, } \\
\text { Ramakrishnan e } \\
\text { Hishan (2018). }\end{array}$ \\
\hline $\begin{array}{l}\text { Materialidade do Intangí- } \\
\text { vel (MI) }\end{array}$ & $\begin{array}{l}\text { Valor contábil dos ativos intangíveis / } \\
\text { Valor contábil do ativo total }\end{array}$ & $\begin{array}{l}\text { Base de dados } \\
\text { Economática }\end{array}$ & $\begin{array}{l}\text { Mota, Brandão, } \\
\text { Ponte (2016) }\end{array}$ \\
\hline Variáveis de controle & Métrica & Fonte de dados & Autores \\
\hline Tamanho (TAM) & $\begin{array}{l}\text { Logaritmo natural do valor contábil dos } \\
\text { ativos totais da empresa }\end{array}$ & $\begin{array}{l}\text { Banco de dados } \\
\text { Economática }\end{array}$ & $\begin{array}{l}\text { Medrado et al. } \\
(2016) \text {. }\end{array}$ \\
\hline $\begin{array}{l}\text { Crescimento das vendas } \\
\text { (CVendas) }\end{array}$ & $\begin{array}{l}\text { (Vendas do ano } 2 \text { - vendas do ano } 1 \text { )/ } \\
\text { vendas do ano } 1\end{array}$ & $\begin{array}{l}\text { Banco de dados } \\
\text { Economática }\end{array}$ & $\begin{array}{l}\text { Arrighetti et al. } \\
\text { (2014); Astawa et al. } \\
(2015) \text {. }\end{array}$ \\
\hline $\begin{array}{l}\text { Nível de governança } \\
\text { corporativa (NGC) }\end{array}$ & $\begin{array}{l}\text { Variável dummy, sendo } 1 \text { para as } \\
\text { empresas com nível diferenciado de } \\
\text { governança corporativa e } 0 \text { para as } \\
\text { demais. }\end{array}$ & Site da $[\mathrm{B}]^{3}$ & $\begin{array}{l}\text { Mazzioni, Carpes e } \\
\text { Lavarda (2014). }\end{array}$ \\
\hline Setor & $\begin{array}{l}\text { Variável dummy, sendo } 1 \text { para as } \\
\text { empresas do setor utilidade pública e } 0 \\
\text { para as demais. }\end{array}$ & $\begin{array}{l}\text { Banco de dados } \\
\text { Economática }\end{array}$ & \\
\hline
\end{tabular}

Fonte: Os autores, 2020.

Em virtude de que a probabilidade do teste de Breuchs-Pagan mostrou-se significante ao nível de 95\%, corrigiu-se a heterocedasticidade por meio da correção de White. Em relação ao teste Durbin-Watson, Field (2009) argumenta que sua finalidade é testar a suposição de independência dos erros e uma das regras é que os valores estatísticos dos testes no intervalo de 1,5 a 2,5 são relativamente normais e valores fora desse intervalo pode ser motivo de preocupação. Portanto, os resultados foram validados.

O fator de inflação de variância (VIF) em todos os modelos indicam valores menores que 10 e maiores que 1 , sendo assim, a multicolinearidade não é problemática, tendo em vista que valores abaixo de 0,10 e acima de 10 indicam problemas sérios (FIELD, 2009). 


\section{Análise e discussão dos resultados}

Esta seção apresenta a análise dos resultados, iniciando-se pela estatística descritiva das variáveis quantitativas, apresentada na Tabela 1. Observa-se que a intangibilidade média das empresas é 9,17\%, o índice médio de RSC é de 13,49, o crescimento médio das vendas é de 79,70\% e o tamanho médio é de R\$18.119.940,47. Os dados também evidenciam uma elevada dispersão entre as empresas a partir do desvio padrão apresentado.

Tabela 1 - Estatística descritiva das variáveis quantitativas

\begin{tabular}{l|l|l|l|l|l}
\hline Variável & Mínimo & Máximo & Média & Mediana & Desvio padrão \\
\hline MI & 0,0000 & 0,8304 & 0,0917 & 0,0056 & 0,1713 \\
RSC & 0,0000 & 73,0000 & 13,4900 & 0,0000 & 24,4050 \\
Cvend & $-0,8834$ & 126,4857 & 0,7970 & 0,1067 & 9,1043 \\
TAM & 9.064 & 860.473 .000 & $18.119 .940,47$ & 3.741 .671 & $69.089 .136,67$ \\
\hline
\end{tabular}

Fonte: Os autores, 2020.

Na Tabela 2 apresenta-se a frequência das variáveis categóricas.

Tabela 2 - frequência das variáveis categóricas

\begin{tabular}{l|l|l|l|l}
\hline Variável & Sim & $\%$ & Não & $\%$ \\
\hline NGC & 106 & 54,92 & 87 & 45,08 \\
Setor (UP) & 36 & 18,65 & 157 & 81,35 \\
\hline
\end{tabular}

Fonte: Os autores, 2020.

Observa-se que das 193 empresas listadas na $[\mathrm{B}]^{3}$ que compõe a amostra, 106 (54,92\%) possuem nível diferenciado de governança corporativa e 87 (45,08\%) são do segmento tradicional. Observa-se também que 36 companhias $(18,65 \%)$ pertencem ao setor utilidade pública enquanto $157(81,35 \%)$ pertencem aos demais setores.

Para verificar a influência das variáveis independentes e de controle sobre a geração de valor adicionado, foram elaborados diversos modelos econométricos, conforme apresentado na Tabela 3. 
Tabela 3 - Influência da RSC e da Intangibilidade na geração de valor adicionado

\begin{tabular}{|c|c|c|c|c|c|}
\hline \multicolumn{4}{|c|}{ Variável dependente: geração de valor adicionado (VA) } & \multicolumn{2}{|l|}{$\mathrm{N}=193$} \\
\hline Variáveis explicativas & $\begin{array}{l}\text { Coeficiente } \\
\text { modelo } 1\end{array}$ & $\begin{array}{l}\text { Coeficiente } \\
\text { modelo } 2\end{array}$ & $\begin{array}{l}\text { Coeficiente } \\
\text { modelo } 3\end{array}$ & $\begin{array}{l}\text { Coeficiente } \\
\text { modelo } 4\end{array}$ & $\begin{array}{l}\text { Coeficiente } \\
\text { modelo } 5\end{array}$ \\
\hline MI & $0.721073 *$ & & $0.7410644^{*}$ & $2.283922 * * *$ & $0.746778^{*}$ \\
\hline $\mathrm{RSC}$ & 0.0004266 & -0.0018374 & 0.0026139 & $-0.3025854 * * *$ & $0.0082336 * * *$ \\
\hline $\mathrm{RSC} * \mathrm{MI}$ & & 0.0172487 & & & \\
\hline Cvend & $-0.0201344 * * *$ & $-0.0202035 * * *$ & & $-0.0394257 * * *$ & $-0.0198685 * * *$ \\
\hline RSC $*$ Cvend & & & $-0.0116701 * * *$ & & \\
\hline TAM & $0.9201484 * * *$ & $0.9380557 * * *$ & $0.9108508 * * *$ & & $0.9095031 * * *$ \\
\hline RSC*TAM & & & & $0.0199136 * * *$ & \\
\hline NGC & -0.1437705 & -0.166945 & -0.0765022 & $1.002278 * * *$ & \\
\hline RSC*NGC & & & & & $-0.0101032 * * *$ \\
\hline Setor & 0.1364603 & 0.158908 & 0.1441715 & $1.4269 * * *$ & 0.1474916 \\
\hline Constante & -0.1189405 & -0.300428 & -0.0351599 & $12.17838 * * *$ & -0.0351172 \\
\hline Estatística F & $509.38 * * *$ & $530.79 * * *$ & $209.94 * * *$ & $411.31 * * *$ & $564.70 * * *$ \\
\hline $\mathrm{R}^{2}$ ajustado & 0.8177 & 0.8154 & 0.8176 & 0.5139 & 0.8194 \\
\hline Tolerance & 0.52 a 0.92 & 0.54 a 0.97 & 0.52 a 0.97 & 0.89 a 1.00 & 0.21 a 0.97 \\
\hline VIF & 1.03 a 1.91 & 1.03 a 1.85 & 1.02 a 1.92 & 1.00 a 1.12 & 1.03 a 4.77 \\
\hline DW & 1.566264 & 1.548043 & 1.627521 & 1.560112 & 1.580428 \\
\hline Breuch- Pagan & 0.0064 & 0.0047 & 0.0536 & 0.0233 & 0.0032 \\
\hline
\end{tabular}

Fonte: Os autores, 2020.

O modelo 1 da Tabela 3 apresenta as variáveis independentes e de controle individualmente. Os demais modelos (2 a 5) consideram a geração do valor adicionado com a moderação da RSC com as demais variáveis. Nos modelos 2 a 5, quando utilizado o fator de moderação excluiu-se a variável original, para evitar problemas de colinearidade.

Os resultados evidenciados na Tabela 3 indicam que os cinco modelos apresentados foram validados, sendo que as variáveis independentes e de controle apresentaram significância estatística para explicar a geração de valor adicionado (estatística F). Por sua vez, o poder explicativo dos modelos foi elevado, sendo superior a $81 \%$ em quatro modelos e superior a $51 \%$ em outro modelo, confirmando sua adequação.

A análise isolada da materialidade do intangível mostrou relação positiva com a geração de valor adicionado em quatro modelos, revelando que os intangíveis aumentam a geração de riqueza das organizações. Os resultados confirmam a hipótese $\mathrm{H}_{1}$ (os ativos intangíveis afetam positivamente a geração de valor adicio- 
nado) e consistentes com os achados de Mazzioni, Moura e Hein, (2014), Dallabona et al. (2015) e Silva et al. (2019). O resultado atende ao pressuposto de que a intangibilidade afeta positivamente o desempenho das empresas conforme defendido por Kayo et al. (2006), Perez e Famá (2006), Carvalho et al. (2010), Parisi e Hockerts (2011), González (2014), Machado et al. (2017), Medeiros e Mól (2017), Albuquerque Filho (2019) e Ferla et al. (2019).

Em relação à hipótese $\mathrm{H}_{2}$ (a Responsabilidade Social Corporativa afeta a geração de valor adicionado), os modelos não indicaram resultados consistentes. Ao se excluir a variável tamanho (modelo 4), a variável RSC assume significância estatística (1\%), de modo negativo com a geração de valor adicionado, enquanto ao se excluir a variável NGC, assume significância estatística (1\%) de modo positivo, alterando o comportamento em relação ao modelo sem moderação (modelo 1).

$\mathrm{H}_{2}$ : a Responsabilidade Social Corporativa afeta a geração de valor adicionado.

O resultado positivo da influência da RSC na geração de valor adicionado é consistente com os achados de Callan, Thomas (2009), Marti, Rovira-Val e Drescher (2015), evidenciando que os investimentos em RSC além de servir como diferencial competitivo melhora o desempenho das empresas. Esta relação positiva entre RSC e desempenho organizacional também foi documentado por Martínez-Ferrero e Frías-Aceituno (2015), Busch e Friede (2018) e Hou (2018), cujos estudos apontam que a RSC apresenta significância para melhor desempenho financeiro.

A variável crescimento de vendas mostrou influência negativa e estatisticamente significativa (1\%) em todos os modelos, revelando que empresas com menor crescimento das vendas apresentam maior capacidade de gerar valor adicionado. Este resultado diverge dos achados de Dallabona, Kroetz e Mascarello (2014) e de Nunes e Miranda (2016), de que quanto maior o crescimento das vendas maior é a capacidade de gerar valor adicionado aos sócios, acionistas, governo e colaboradores. Uma explicação possível é de que em momentos de busca por participação de mercado, as empresas podem sacrificar temporariamente o incremento de valor adicionado.

A variável tamanho mostrou influência positiva e estatisticamente significativa em todos os modelos que foi incluída (1\%), revelando que empresas maiores apresentam maior capacidade de gerar valor adicionado, consistente com os achados de Kayo et al. (2006) e de Parente et al. (2015). Empresas maiores podem ter mais condições para redução dos custos no acesso ao crédito, a bens de capital e insumos, proporcionado elevação no valor adicionado produzido (Machado et al., 2015).

O modelo 4 indicou influência positiva da governança corporativa na geração de valor adicionado, consistente com os achados de Barros et al. (2013) e Machado e Famá (2011). O resultado atende ao pressuposto de que empresas com elevado NGC investem mais em ativos intangíveis e consequentemente contribuem na geração de valor adicionado, conforme defendido por Rives e Bañón (2008) e Girioli et al. (2014).

O setor (utilidade pública) só mostrou influência positiva e estatisticamente significativa (1\%), no modelo em que foi retirada a variável tamanho (modelo 4), consistente com os achados de Mazzioni, Carpes e Lavarda (2014). O resultado atende ao pressuposto de que existe relação positiva entre ativos intangíveis e 
geração de valor adicionado, conforme defendido por Mazzioni, Moura e Hein (2014).

Em relação ao papel moderador da RSC para a geração de valor adicionado, constatou-se que: com a intangibilidade, reduziu a força da influência e excluiu a significância positiva (modelo 2). Este resultado permite refutar a hipótese de que os ativos intangíveis afetam positivamente a relação entre a responsabilidade social corporativa e a geração de valor adicionado $\left(\mathrm{H}_{3}\right)$. Com o crescimento de vendas, a moderação reduziu a força da influência e manteve a significância negativa (modelo 3); com o NGC, a moderação reduziu a força da influência negativa, mas concedeu significância (modelo 5).

Os resultados corroboram os estudos de Branco e Rodrigues (2006), pois sustentam que o engajamento nas ações de RSC decorre em custos, pela necessidade de investir em novos equipamentos, implantação de controles mais rigorosos, investimentos em programas de saúde e segurança. A divulgação das atividades socialmente responsáveis também gera custos com a coleta de dados, comunicação e auditoria, ou seja, a empresa que investe em práticas de RSC arca com custos no curto prazo, com o objetivo de obter benefícios futuros, que poderão reverter apenas no longo prazo.

\section{Considerações finais}

Os achados da pesquisa mostram o efeito positivo da intangibilidade sobre a geração de riquezas. Esse resultado esperado correspondeu à hipótese de que os ativos intangíveis afetam positivamente a geração de valor adicionado. Quanto à hipótese de que a RSC afeta a geração de valor adicionado, de forma direta, o efeito mostrou-se inconsistente.

Uma explicação para esses resultados não conclusivos pode decorrer do fato de que os dados analisados são relativos a um exercício e que os resultados econômicos do investimento socioambiental possam demorar mais tempo para se manifestar. Vários estudos prévios, a exemplo de Callan e Thomas (2009), Peixoto, Santos e Luz (2017), Duque, Silva e Cohen (2019), Marti, Rovira-Val, Drescher (2015), Busch e Friede (2018), Hou (2018), concluíram que a RSC afeta positivamente no desempenho das empresas. Por outro lado, evidencias contrárias também foram identificadas nos estudos de Roque e Cortez (2006), Oliveira e Silva (2010), Machado (2011), Zanelato et al. (2015), Vergini et al. (2015).

O estudo não valida a hipótese de que os ativos intangíveis afetam positivamente a relação entre a responsabilidade social corporativa e a geração de valor adicionado. Contudo, reforçou que empresas maiores se mostraram mais consistentes na produção de riquezas.

As inovações do estudo estão relacionadas com as moderações realizadas da RSC com outras características organizacionais. A moderação da RSC e crescimento das vendas mostrou significância negativa a 1\% (modelo 3), com o tamanho apresentou significância positiva a 1\% (modelo 4) e com boas práticas de governança corporativa a significância mostrou-se negativa a 1\% (modelo 5).

$\mathrm{O}$ estudo contribui com a literatura prévia ao inferir que a maior presença concomitante de investimentos em ativos intangíveis e de investimentos em Responsabilidade Social Corporativa proporciona redução na 
geração de riquezas, contrariando os pressupostos individuais de cada elemento.

Apesar dos insights possíveis, os resultados devem ser considerados com parcimônia, em decorrência de ter avaliado um ano apenas. Para estudos futuros, sugere-se ampliar o período de análise e avaliar se a moderação produz efeitos distintos entre os diversos setores econômicos. Outra perspectiva é avaliar se os efeitos sobre variáveis de mercado confirmam os achados do estudo ou apresentam resultados distintos.

\section{Referências}

ALBUQUERQUE FILHO, A.R. Efeito da competitividade e da governança corporativa no nível de intangibilidade das companhias familiares. NAVUS - Revista de Gestão e Tecnologia, v. 9, n. 3, p. 143-155, 2019. DOI: https://doi.org/10.22279/navus.2019.v9n3.p143-155.943.

ANDONOVA, V.; RUÍZ-PAVA, G. The role of industry factors and intangible assets in company performance in Colombia. Journal of Business Research, v. 69, n. 10, p. 4377-4384, 2016. DOI: 10.1016 / j.jbusres.2016.03.060.

ARMINEN, H.; PUUMALAINEN, K.; PATARI, S.; FELLNHOFER, K. Corporate social performance: Inter-industry and international differences. Journal of Cleaner Production, v. 177, p. 426-437, 2018. DOI: 10.1016 / j.jclepro.2017.12.250.

ARRIGHETTI, A.; LANDINI, F.; LASAGNI, A. Intangible assets and firm heterogeneity: Evidence from Italy. Research Policy, v. 43, n. 1, p. 202-213, 2014. DOI: 10.1016 / j.respol.2013.07.015.

ASTAWA, I.P.; SUDIKA, I.P.; YULIARMI, N.N. Intangible capital and leverage to improve financial performance of LPG Agents in Bali. Procedia-Social and Behavioral Sciences, v. 211, p. 149-156, 2015. DOI: 10.1016 / j.sbspro.2015.11.022.

BARROS, C.M.E.; CATAPLAN, A.; SCHERER, L.M.; ISIDORO, C. Relevância do valor adicionado: um estudo empírico em sociedades anônimas abertas brasileiras. Registro Contábil, v. 4, n. 3, p. 147-162, 2013.

BRANCO, M.C.; RODRIGUES, L.L. Corporate social responsibility and resource-based perspectives. Journal of Business Ethics, v. 69, n. 2, p. 111-132, 2006. DOI: https://doi.org/10.1007/s10551-006-9071-z.

BUSCH, T.; FRIEDE, G. The robustness of the corporate social and financial performance relation: A second-order meta-analysis. Corporate Social Responsibility and Environmental Management, v. 25, n. 4, p. 583-608, 2018. DOI: https://doi.org/10.1002/csr.1480.

CALLAN, S.J.; THOMAS, J.M. Corporate financial performance and corporate social performance: an update and reinvestigation. Corporate Social Responsibility and Environmental Management, v. 16, p. 61-78, 2009. DOI: https://doi.org/10.1002/csr.182.

CARVALHO, F.M.; KAYO, E.K.; MARTIN, D.M.L. Tangibilidade e intangibilidade na determinação do 
desempenho persistente de firmas brasileiras. Revista de Administração Contemporânea, v. 14, n. 5, p. 871-889, 2010.

CASTRO, L.A. Análise de diferenças de desempenho entre empresas participantes e não participantes do Índice de Sustentabilidade Empresarial da BM\&FBOVESPA. Revista Ciências Administrativas ou Journal of Administrative Sciences, v. 23, n. 1, p. 128- 155, 2016. DOI: http://dx.doi.org/10.5020/23180722.23.1.128-155.

CHONG, W.N.; TAN, G. Obtaining intangible and tangible benefits from corporate social responsibility. International Review of Business Research Papers. v. 6, n. 4, p. 360-371. 2010.

COMITÊ DE PRONUNCIAMENTOS CONTÁBEIS. Pronunciamento Técnico CPC 04 - Ativos Intangíveis. 2010. Disponível em: www.cpc.org.br. Acesso em: 20 mar. 2019.

CRAMER, J. Corporate social responsibility: lessons learned. Environmental Quality Management, v. 13, n. 2, p. 59-66, 2003.

CRAWFORD, R. Na era do capital humano. São Paulo: Atlas, 1994.

DALLABONA, L.F.; KROETZ, M.; MASCARELLO, G. Relação entre os indicadores de desempenho e o valor adicionado distribuído aos agentes colaboradores de empresas listadas na BM\&FBovespa. Revista Catarinense da Ciência Contábil, v. 13 n. 39, p. 49-63, 2014.

DOI: http://dx.doi.org/10.16930/2237-7662/rccc.v13n39p49-63.

DALLABONA, L.F.; MAZZIONI, S.; KLANN, R.C. A Influência do Grau de Intangibilidade no Desempenho de Empresas Sediadas nos Países com Turbulência Econômica. RACE: Revista de Administração, Contabilidade e Economia, v. 14, n. 3, p. 1035-1062, 2015. DOI: https://doi.org/10.18593/race.v14i3.4204.

DUQUE, L.P.D.; SILVA, J.F.; COHEN, M. Impactos da responsabilidade social corporativa no desempenho de indústrias: teste empírico nas operadoras brasileiras de planos de saúde e odontológicos. Revista Ibero-Americana de Estratégia, v. 18, n. 2, p. 188-204, 2019.

FERLA, R.; MULLER, S.; KLANN, R. Influência dos ativos intangíveis no desempenho econômico de empresas latino-americanas. Brazilian Review of Finance, v. 17, n. 35, p. 35-50, 2019. DOI: 10.12660/rbfin. v17n1.2019.63869.

FIELD, A. Descobrindo a estatística usando o SPSS. 2 ed. Porto Alegre: Artmed, 2009.

GANGI, F.; D'ANGELO, E. The virtuous circle of corporate social performance and corporate social disclosure. Modern Economy, v. 9, p. 1396-1418, 2016. DOI: 10.4236/me.2016.712129.

GIL, A.C. Métodos e técnicas de pesquisa social. 6. ed. São Paulo: Atlas, 2010.

GIRIOLI, L.S.; DE SOUZA, E.F.S.; NOGUEIRA, I.V.; CALIL, J.F. Análise da criação de valor de empresas listadas na BM\&FBOVESPA nos diferentes níveis de governança corporativa no período de 2008 a 
2012. Revista de administração da UNIMEP, v. 12, n.1, p. 178-203, 2014. DOI: 10.15600/1679-5350/rau. v12n1p178-203.

GONZÁLEZ R.Z.F. Intangibles of CSR in the tourism sector. International Journal of Business and Social Research, 4, 2, 15-23, 2014. DOI: http://dx.doi.org/10.18533/ijbsr.v4i2.396.

GRECEANU, D.V.A responsabilidade social corporativa e a avaliação dos ativos intangíveis. Revista Universo Contábil, v. 4, n. 2, p. 127-143, abr./jun. 2008. DOI: http://dx.doi.org/10.4270/ruc.20084.

HALLER, A.; STOLOWY, H. Valued added in financial accounting, a comparative study of Germany and France. Advances in International Accounting, v. 11, p. 23-51, 1998.

HOU, T. C-T. The relationship between corporate social responsibility and sustainable financial performance: firm-level evidence from Taiwan. Corporate Social Responsibility Environmental Management, v. 26, p. 19-28, 2019. DOI: https://doi.org/10.1002/csr.1647.

KAYO, E.K.; KIMURA, H.; MARTIN, D.M.L.; NAKAMURA, W.T. Ativos intangíveis, ciclo de vida e criação de valor. Revista de Administração Contemporânea, v. 10, n. 3, p. 73-90, 2006. DOI: https://doi. org/10.1590/S1415-65552006000300005.

KEONG, L.B.; RAMAKRISHNAN, S.; HISHAN, S.S. Corporate social responsibility practice of Malaysian public listed government-linked companies: A dimensional analysis. Management Science Letters, v. 8, n. 5, p. 417-426, 2018. DOI: 10.5267 / j.msl.2018.4.005.

LORENA, A. The relation between corporate social responsibility and bank reputation: a review and roadmap. European Journal of Economics and Business Studies, v. 4, n. 2 , May-August, 2018. DOI: 10.2478/ejes-2018-0034.

LUCA, M.M.M.; CUNHA, J.V.A.; RIBEIRO, M.S.; OLIVEIRA, M.C. Demonstração do valor adicionado: do cálculo da riqueza criada pela empresa ao valor do PIB. 2. ed. São Paulo: Atlas, 2009.

MACHADO, G.A.; CARVALHO, L.; PEIXOTO, F.M. A relação entre intensidade tecnológica e grau de intangibilidade no desempenho econômico-financeiro da indústria brasileira. Revista Gestão \& Regionalidade, v. 33, n. 99, p. 1-18, 2017. DOI: https://doi.org/10.13037/gr.vol33n99.4167.

MACHADO, J.H.; FAMÁ, R. Ativos intangíveis e governança corporativa no mercado de capitais brasileiro. Revista Contemporânea de Contabilidade, v. 8, n. 16, p. 89-110, 2011. DOI: 10.5007/2175-8069.2011v8n16p89.

MACHADO, L.K.; PRADO, J.W.; VIEIRA, K.C.; ANTONIALLI, L.M. A relevância da estrutura de capital no desempenho das firmas: uma análise multivariada das empresas brasileiras de capital aberto. Revista de Educação e Pesquisa em Contabilidade, v. 9 n. 4, p. 397-414, 2015. DOI: http://dx.doi.org/10.17524/repec.v9i4.1313.

MACHADO, M.A.V.; MACHADO, M.R. Responsabilidade social impacta o desempenho financeiro 
das empresas? ASAA - Advances in Scientific and Applied Accounting, v. 4, n. 1, p. 2-23, 2011. DOI: 10.14392/ASAA.2011040101.

MADORRAN, C.; GARCIA, T. Responsabilidade social corporativa e desempenho financeiro caso espanhol. Revista de Administração de Empresas, v. 56, n. 1, p. 20-28, 2016. DOI: http://dx.doi.org/10.1590/ S0034-759020160103.

MADSEN, P.M.; RODGERS, Z.J. Looking good by doing good: The antecedents and consequences of stakeholder attention to corporate disaster relief. Strategic Management Journal, v. 36, p. 776-794, 2015. https://doi.org/10.1002/smj.2246.

MARTI, C.P.; ROVIRA-VAL, M.R.; DRESCHER, L.G.J. Are firms that contribute to sustainable development better financially? Corporate Social Responsibility and Environmental Management, v. 22, p. 305319, 2015. https://doi.org/10.1002/csr.1347.

MARTÍNEZ-FERRERO, J.; FRÍAS-ACEITUNO, J.V. Relationship between sustainable development and financial performance: international empirical research. Business Strategy and the Environment, v. 24, p. 20-39, 2015. https://doi.org/10.1002/bse.1803.

MAZZIONI, S.; CARPES, A.M.S.; LAVARDA, C.E.F. A relação entre o grau de intangibilidade e a geração de valor adicionado em empresas brasileiras de capital aberto. Enfoque Reflexão Contábil, v. 33, n. 2, p. 71-86, 2014. DOI: 10.4025/enfoque.v33i2.22298.

MAZZIONI, S.; MOURA, G.D.; HEIN, N. Distribuição de valor adicionado e intangibilidade: uma análise em empresas brasileiras. Revista de Contabilidade e Organizações, v. 8, p. 50-64, n. 20, 2014. DOI: https://doi.org/10.11606/rco.v8i20.5.

MEDEIROS, A.W.; MÓL, A.L.R. Tangibilidade e Intangibilidade na Identificação do Desempenho Persistente: Evidências no Mercado Brasileiro. Revista de Administração Contemporânea, v. 21, n. 2, p. 184 202, 2017. DOI: http://dx.doi.org/10.1590/1982-7849rac2017150259.

MEDRADO, F.; CELLA, G.; PEREIRA, J.V.; DANTAS, J.A. Relação entre o nível de intangibilidade dos ativos e o valor de mercado das empresas. Revista de Contabilidade e Organizações, v. 10, n. 28, p. 32-44, 2016. DOI: http://dx.doi.org/10.11606/rco.v10i28.119480.

MOTA, A.F.; BRANDÃO, I.F.; PONTE, V.M.R. Disclosure e materialidade: evidências nos ativos intangíveis dos clubes brasileiros de futebol. RACE: Revista de Administração, Contabilidade e Economia, v. 15, n. 1, p. 175-200, 2016. DOI: http://dx.doi.org/10.18593/race.v15i1.6326.

MOURA, G.D. Conformidade do disclosure obrigatório dos ativos intangíveis e práticas de governança corporativa: uma análise de empresas listadas na Bovespa. 2011. 132 f. Dissertação (Mestrado) - Programa de Pós-Graduação em Ciências Contábeis da Universidade Regional de Blumenau, Blumenau, 2011.

NEVES, J.C.; ALBUQUERQUE, F. Imposto de renda de empresas portuguesas de capital aberto em relatórios financeiros e de responsabilidade social corporativa. Revista brasileira de gestão de negócios, v. 21 , n. 
3, p. 464-485, 2019. DOI: 0.7819/rbgn.v21i3.4009.

NUNES, V.M.; MIRANDA, G.J. Geração e Distribuição do Valor Adicionado em 2013: Análise das Companhias Listadas no IBrX-100. Revista Evidenciação Contábil \& Finanças, v. 4, n. 1, p. 18-32, 2016. DOI: $10.18405 /$ recfin20160102.

OLIVEIRA, R.M.; SILVA JUNIOR, A.; SILVA, A.R.L. Relação entre o investimento social corporativo e o valor das empresas brasileiras. Revista de Educação e Pesquisa em Contabilidade, v. 4, n. 2, p. 62-80, 2010. DOI: https://doi.org/10.17524/repec.v4i2.201.

ORLITZKY, M.; SCHMIDT, F.L.; RYNES, S.L. Corporate social and financial performance: a meta-analysis. Organization Studies, v. 24, p. 403-441, 2003. DOI: 10.1177 / 0170840603024003910.

PARENTE, P.H.N.; LUCA, M.M.M.; VASCONCELOS, A.C. Teoria contingencial e intangibilidade: um estudo nas empresas listadas na BM\&FBovespa. Enfoque Reflexão Contábil, v. 34, n. 3, p. 21-40, 2015. DOI: $10.4025 /$ enfoque.v34i3.29568.

PARISI, C.; HOCKERTS, K. Causal maps and the performance measurement of CSR related intangibles: A case study. International Journal of Learning and Intellectual Capital, v. 8, n. 3, p. 290-309, 2011.

PEIXOTO, E.P.A.; SANTOS, R.R.; LUZ, J.R.M. Relação da evidenciação dos gastos ambientais e desempenho econômico-financeiro de empresas potencialmente poluidoras do brasil. Revista do Mestrado em Ciências Contábeis da UERJ, v. 22, n. 3, p. 36-53, 2017.

PEREZ, M.M.; FAMÁ; R. Ativos intangíveis e o desempenho empresarial. Revista Contabilidade e Finanças, v. 17, n. 40, p. 7-24, 2006. DOI: https://doi.org/10.1590/S1519-70772006000100002.

POPOLI, P., 2015. Reinforcing intangible assets through CSR in a globalized world. Journal of Management Policies and Practices, v. 3, n. 1, p. 3, 23-30. DOI: 10.15640/jmpp.v3n1a4.

RIVES, J.L.M.; BAÑÓN, A.R. La responsabilidad social, corporativa como determinante del éxito competitivo: Un análisis empírico. Revista Europea de Dirección y Economía de la Empresa, v. 17, n. 3, p. 27-42, 2008.

ROBINSON, M.; KLEFFNER, A.; BERTELS, S. Signaling sustainability leadership: empirical evidence of the value of Djsi membership. Journal of Business Ethics, v. 101, n. 3, p. 493-505, 2011. DOI: 10.1007 / s10551-011-0735-y.

ROQUE, V.; CORTEZ, M.C. A divulgação de informação ambiental e a performance financeira das empresas cotadas em Portugal. Revista de Estudos Politécnicos, v. 3, n. 5, p. 119-143, 2006.

SEARCY, C.; ELKHAWAS, D. Corporate sustainability ratings: an investigation into how corporations use the Dow Jones Sustainability Index. Journal of Cleaner Production, v. 35, p. 79-92, 2012. DOI: 10.1016 / j.jclepro.2012.05.022. 
SILVA, A.R.; CALLADO, A.L.C.; BOMFIM, E.T. Influência do nível de intangibilidade no desempenho das companhias brasileiras. Revista Científica Hermes, n. 24, 2019. DOI: http://dx.doi.org/10.21710/rch.v24i0.

SILVA, R.S.; BOAVENTURA, J.M.G.; MELLO, R.B. Metanálise da relação entre a performance social e a performance financeira corporativa. Gestão \& Produção, n. 4, v. 25, p. 764-776, 2018. DOI: https://doi. org/10.1590/0104-530x025-18.

SVEIBY, K.E. A nova riqueza das organizações: gerenciando e avaliando patrimônios. Rio de Janeiro: Campus, 1998.

VERGINI, D.P.; TURRA, S.; JACOMOSSI, F.A.; HEIN, N. Impacto da responsabilidade social no desempenho das empresas brasileiras componentes do Dow Jones Sustainability Index. Revista Eletrônica em Gestão, Educação e Tecnologia Ambiental, v. 19, n. 2, p. 879 - 898, 2015. DOI: 105902/2236117015846.

VOGT, M.; KREUZBERG, F.; DEGENHART, L.; RODRIGUES JUNIOR, M.M.; BIAVATTI, V.T. Relação entre intangibilidade, desempenho econômico e social das empresas listadas na BM\&FBovespa. Gestão \& Regionalidade, v. 32, n. 95, p. 71-89, 2016. DOI: 10.13037/gr.vol32n95.2741.

WANG, Y.G. Corporate social responsability and stock performance-evidence from Taiwan. Modern Economy, 2011. DOI: :10.4236/me.2011.25087.

ZANELATO, F.A.; GRANDO, T.; MARTINS, V.D.; ZANINI, F.A.M. Gastos sociais internos e o desempenho das empresas do ISE. Revista Ambiente Contábil, v. 10, n. 2, p. 384 - 403, 2018. DOI: https://doi. org/10.21680/2176-9036.2018v10n2ID14157. 